\title{
PENINGKATAN KOMITMEN ORGANISASI MELALUI PENGEMBANGAN BUDAYA ORGANISASI DAN KEPUASAN KERJA
}

\author{
Dwi Rahmanendra ${ }^{1}$, Eka Suhardi ${ }^{2}$ \\ ${ }^{1}$ Widyaiswara Pusat Pendidikan dan Pelatihan SDM Lingkungan Hidup dan Kehutanan, \\ Kementerian Lingkungan Hidup dan Kehutanan Bogor. \\ ${ }^{2}$ Program Pascasarjana Universitas Pakuan, \\ Email: pasca@unpak.ac.id
}

\begin{abstract}
The purpose of this study is to find the efforts to increase the organizational commitment of the Ministry of Environment and Forestry (KLHK) trainers through a study on its relationship with organizational culture and job satisfaction. This study population consist of 133 trainers who are on active duty at the KLHK Education and Training Institute where the total sample are 100 trainers, as well as using Slovin's Formula with an error tolerance of 5\%. The data are collected through questionnaire and it analized by a descriptive and inferential statistic analysis. The results show three positive and significant relationships. Firstly, is the relationship between organizational culture and organizational commitment of KLHK trainers' with a correlation coefficient of 0.779. Secondly, is the relationship between job satisfaction and organizational commitment of KLHK trainers' with a correlation coefficient of 0.640. Thirdly, is the relationship between organizational culture and job satisfaction together with organizational commitment of KLHK trainers' with a correlation coefficient of 0.802 .
\end{abstract}

Keywords: Organizational Culture, Job Satisfaction, Organizational Commitment.

\begin{abstract}
ABSTRAK
Penelitian ini bertujuan untuk menemukan upaya-upaya yang dapat dilakukan dalam rangka meningkatkan komitmen organisasi Widyaiswara KLHK melalui kajian terhadap hubungannya dengan budaya organisasi dan kepuasan kerja. Populasi penelitian berjumlah 133 widyaiswara yang sedang bertugas aktif di Lembaga Diklat Lingkup Kementerian LHK, dengan jumlah sampel sebanyak 100 orang, yang penentuannya menggunakan rumus Slovin dengan toleransi kesalahan sebesar 5\%. Data dikumpulkan menggunakan instrumen dalam bentuk kuesioner dan dianalisis dengan analisis statistik deskriptif dan inferensial. Hasil penelitian menunjukkan tiga hubungan yang positif dan signikan. Pertama, terdapat hubungan yang positif dan signifikan antara budaya organisasi dengan komitmen organisasi Widyaiswara KLHK dengan nilai koefisien korelasi sebesar 0,779 . Kedua, terdapat hubungan yang positif dan signifikan antara kepuasan kerja dengan komitmen organisasi Widyaiswara KLHK dengan nilai koefisien korelasi sebesar 0,640. Ketiga, terdapat huhungan yang positif dan signifikan antara budaya organisasi dan kepuasan kerja secara bersama-sama dengan komitmen organisasi Widyaiswara KLHK dengan nilai koefisien korelasi sebesar 0,802.
\end{abstract}

Kata Kunci : Budaya Organisasi, Kepuasan Kerja, Komitmen Organisasi. 


\section{PENDAHULUAN}

Pembangunan sektor lingkungan hidup dan kehutanan akan dapat dilakukan dengan efektif dan mencapai tujuan yang diinginkan jika dalam pelaksanaannya didukung oleh sumberdaya manusia yang kompeten dan profesional, baik aparatur maupun parapihak lain yang terlibat didalamnya. Peningkatan profesionalisme dan kompetensi sumberdaya manusia lingkungan hidup dan kehutanan, salah satunya dapat dilakukan melalui proses pendidikan dan pelatihan (diklat) yang diselenggarakan oleh Lembaga Diklat Lingkup KLHK.

Sebuah lembaga diklat akan dapat menjalankan tugasnya dengan baik, manakala seluruh komponen tenaga kediklatan yang terdiri dari pengajar (widyaiswara), peserta dan penyelenggara, dapat menjalankan fungsinya dengan efektif. Widyaiswara sebagai salah satu pilar penyelenggaraan diklat mempunyai peran yang sangat penting dan strategis dalam upaya pencapaian tujuan dan keberhasilan tugas lembaga diklat. Oleh karenanya widyaiswara dituntut memiliki kompetensi yang handal dalam menjalankan tugas pokok dan fungsi jabatan yang diembannya, yaitu mendidik, mengajar dan melatih PNS serta evaluasi dan pengembangan pendidikan dan pelatihan pada lembaga diklat pemerintah. Tentunya tugastugas yang begitu berat tersebut tidak akan dapat dilaksanakan dengan baik manakala seorang widyaiswara tidak memiliki komitmen yang tinggi terhadap tugas, profesi dan organisasinya. Komitmen organisasi sangat dibutuhkan untuk pengembangan organisasi (Hidayat, 2017)

\section{Komitmen Organisasi}

Schermerhorn (2010: 70), mengemukakan bahwa komitmen terhadap organisasi adalah tingkat loyalitas individu kepada organisasi. Adapun yang menjadi faktor-faktornya adalah : (a) mengidentifikasi dengan kuat terhadap organisasi, dan (b) bangga mempertimbangkan dirinya menjadi anggota organisasi. Robbins dan Timothy (2014: 36) mengemukakan bahwa komitmen organisasi adalah identifikasi oleh seorang karyawan dengan organisasi tertentu dan tujuannya serta keinginannya untuk tetap menjadi anggota organisasi. Sejalan dengan penjelasan tersebut, Kinicki dan Fugate (2016: 50) mengungkapkan bahwa komitmen organisasi mencerminkan sejauh mana seseorang mengidentifikasi diri dengan sebuah organisasi dan berkomitmen terhadap tujuannya.

James L. Gibson (2006: 184) mendefinisikan komitmen terhadap organisasi sebagai perasaan identifikasi, loyalitas dan keterlibatan yang diekspresikan oleh seorang pekerja terhadap organisasi atau unit organisasi. Zohreh, Batoul, dan Alireza (2012: 1529-1538) berpendapat bahwa komitmen organisasi adalah keinginan untuk tinggal lebih lama di dalam organisasi, menampilkan performa dan hasil yang lebih baik untuk organisasi serta bersepakat dengan perubahan organisasi. Sedangkan menurut Terence R. Mitchell dan James R. Larson (2005: 144), komitmen organisasi merupakan sikap seseorang untuk terus berperan serta di dalam organisasi.

Berdasarkan uraian berbagai teori di atas, maka dapat disintesiskan bahwa komitmen terhadap organisasi adalah sikap seseorang dalam menerima nilai-nilai dan tujuan organisasi, keinginan untuk tinggal lebih lama di dalam organisasi, kemauan untuk memberikan hasil yang lebih baik untuk organisasi serta keterlibatan dan loyalitas individu terhadap organisasi.

\section{Budaya Organisasi}

Sutrisno (2011: 2) mengemukakan bahwa budaya organisasi adalah perangkat sistem nilai-nilai (values), keyakinan-keyakinan (benefits) dan asumsi-asumsi (assumtions) atau norma-norma yang telah lama berlaku, disepakati dan diikuti oleh para anggota suatu organisasi sebagai pedoman perilaku dan pemecahan masalah-masalah organisasinya. Rostika (2014: 17) mendefinisikan budaya organisasi sebagai pola asumsi dasar yang diciptakan, ditemukan atau dikembangkan oleh kelompok tertentu saat menyesuaikan diri dengan masalah- 
masalah eksternal dan integrasi internal yang telah bekerja cukup baik serta dianggap berharga, dan karena itu diajarkan pada anggota baru sebagai cara yang benar untuk menyadari, berpikir, dan merasakan hubungan dengan masalah tersebut.

Ivancevich (2007: 44) mengungkapkan bahwa budaya organisasi adalah apa yang dipersepsikan karyawan dan cara persepsi itu menciptakan suatu pola keyakinan, nilai dan ekspektasi. Sedangkan menurut Robbins dan Timothy (2014: 249), budaya organisasi adalah suatu sistem yang mengacu pada makna bersama yang dimiliki oleh anggota yang membedakan organisasi itu dari organisasi lain. Darwis, Djoehana dan Sumardi (2008: 43-44) menyatakan bahwa budaya organisasi adalah seperangkat nilai, yaitu norma-norma yang mengarahkan keyakinan dan pemahaman yang dibentuk para anggota suatu organisasi dan mengajarkannya kepada para anggota baru dengan sebaik mungkin untuk dapat menerapkan nilai atau norma tersebut di dalam kehidupan berorganisasi.

Berdasarkan berbagai uraian teori di atas, maka dapat disintesiskan bahwa budaya organisasi adalah sistem nilai, keyakinan, harapan, norma dan asumsi dasar yang disepakati, dipelajari dan diikuti oleh para anggota organisasi sebagai pedoman berpikir, perilaku dan pemecahan masalah organisasi.

\section{Kepuasan Kerja}

Menurut Ivancevich (2006: 90), kepuasan kerja adalah sikap seseorang terhadap pekerjaannya. Hal tersebut dihasilkan dari persepsi seseorang mengenai pekerjaannya dan tingkat kesesuaian antara individu dan organisasi. Vroom (2006: 185), menyebutkan bahwa kepuasan kerja adalah orientasi sikap individu untuk berperan dalam pekerjaan yang sedang ditekuninya. Menurut Schermerhorn (2010: 72-73), yang dimaksud dengan kepuasan kerja adalah sikap yang merefleksikan perasaan positif dan negatif seseorang terhadap pekerjaan.

Robbin (2006: 94-103), mengemukakan bahwa kepuasan kerja merupakan sikap umum individu terhadap perkerjaannya. Seseorang dengan tingkat kepuasan kerja tinggi menunjukkan sikap yang positif terhadap pekerjaannya, dan seseorang yang tidak puas dengan pekerjaannya menunjukkan sikap yang negatif terhadap pekerjaannya. Fred Luthans (2011: 141), kepuasan kerja adalah hasil dari persepsi karyawan mengenai seberapa baik pekerjaannya memberikan hal yang dinilai penting.

Berdasarkan uraian berbagai teori di atas, dapat disintesiskan bahwa kepuasan kerja adalah sikap umum dan perasaan seseorang berdasarkan penilaian terhadap berbagai aspek pekerjaannya. Adapun indikatornya adalah : (a) kondisi pekerjaan, (b) peluang promosi, (c) gaji, tunjangan dan honorarium, (d) supervisi/pengawasan, dan (e) hubungan dengan rekan kerja.

\section{METODE PENELITIAN}

Metode yang digunakan dalam penelitian ini adalah metode survei dengan pendekatan kuantitatif korelasional, dengan tujuan untuk mengeksplorasi hubungan kausalitas antara variabel-variabel penelitian, yakni sejauhmana variasi dalam satu variabel berhubungan dengan variasi dalam variabel lain.

Populasi dalam penelitian ini adalah seluruh widyaiswara yang sedang bertugas aktif di Lembaga Diklat Lingkup Kementerian LHK yang berjumlah 133 orang, sampel yang digunakan dalam penelitian ini adalah sebanyak 100 orang widyaiswara, sedangkan 30 dari 33 orang widyaiswara yang lainnya digunakan untuk menguji coba instrumen penelitian. Uji coba instrumen dilakukan melalui teknik korelasi Product Moment Pearson. Uji Reliabilitas 
instrumen penelitian menggunakan perhitungan Alpha Cronbach. Sedangkan analisis data menggunakan statistik inferensial dengan menggunakan uji analisis varians regresi.

\section{HASIL PENELITIAN}

\section{Pengujian persyaratan analisis}

\section{Uji Normalitas}

Dari uji yang telah dilakukan diketahui bahwa nilai $\mathrm{L}_{\text {hitung }}=\mathbf{0 , 0 7 3 6}$ dan nilai $\mathrm{L}_{\text {tabel }}=$ $\mathbf{0 , 0 8 8 6}$ (dengan $\mathrm{N}=100$ dan taraf signifikansi $\alpha=0,05$ ). Dengan demikian $\mathrm{L}_{\text {hitung }}<\mathrm{L}_{\text {tabel, }}$ sehingga galat taksiran $\mathrm{Y}$ atas $\mathrm{X}_{1}$ berdistribusi NORMAL.

Dari uji yang telah dilakukan diketahui bahwa nilai $\mathrm{L}_{\text {hitung }}=\mathbf{0 , 0 6 5 1}$ dan nilai $\mathrm{L}_{\text {tabel }}=$ $\mathbf{0 , 0 8 8 6}$ (dengan $\mathrm{N}=100$ dan taraf signifikansi $\alpha=0,05$ ). Dengan demikian $\mathrm{L}_{\text {hitung }}<\mathrm{L}_{\text {tabel, }}$ sehingga galat taksiran $\mathrm{Y}$ atas $\mathrm{X}_{2}$ berdistribusi NORMAL.

\section{Uji homogenitas}

Dari perhitungan yang telah dilakukan diperoleh nilai $\varkappa_{\text {hitung }}^{2}=\mathbf{3 7 , 3 1}$ dan dari Tabel Chi Kuadrat untuk $\alpha=0,05$ dan $\mathrm{dk}=99$ diperoleh $x^{2}{ }_{(0.95 ; 99)}=\mathbf{1 2 3 , 2 3}$, sehingga $x^{2}{ }_{\text {hitung }}<x_{\text {tabel, }}^{2}$, dengan demikian dapat disimpulkan bahwa varians skor $\mathrm{Y}$ yang dikelompokkan atas dasar $\mathrm{X}_{1}$ adalah Homogen.

Dari perhitungan yang telah dilakukan diperoleh nilai $\varkappa^{2}$ hitung $=\mathbf{5 4 , 6 3}$ dan dari Tabel Chi Kuadrat untuk $\alpha=0,05 \mathrm{dan} \mathrm{dk}=99$ diperoleh $x^{2}(0.95 ; 99)=\mathbf{1 2 3 , 2 3}$, sehingga $x^{2}$ hitung $<x^{2}$ tabel, dengan demikian dapat disimpulkan bahwa varians skor $\mathrm{Y}$ yang dikelompokkan atas dasar $\mathrm{X}_{1}$ adalah Homogen.

\section{Pengujian hipotesis}

\section{Hubungan antara Budaya Organisasi (X1) dengan Komitmen Organisasi (Y)}

Berdasarkan output SPSS di atas diperoleh konstanta kemiringan (a) = 29,783 dan koefisien arah (b) $=0,762$. Dengan demikian, hubungan fungsional antara Komitmen Organisasi Widyaiswara KLHK dengan Budaya Organisasi dapat dinyatakan dalam bentuk persamaan regresi $\hat{\mathbf{Y}}=\mathbf{2 9 , 7 8 3}+\mathbf{0 , 7 6 2 X}$.

Setelah diketahui besarnya koefisien korelasi $\left(\mathrm{r}_{\mathrm{y} 1}\right)$, selanjutnya dihitung besarnya kontribusi (koefisien determinasi) Budaya Organisasi terhadap Komitmen Organisasi Widyaiswara KLHK $\left(\mathrm{r}_{\mathrm{y} 1}^{2}\right)$. Dari hasil perhitungan diperoleh nilai koefisien determinasi sebesar $(0,779)^{2}=0,6068$, yang dapat dimaknai bahwa 60,68\% keragaman pada Komitmen Organisasi Widyaiswara KLHK dapat dijelaskan oleh Budaya Organisasi.

\section{Hubungan antara Kepuasan Kerja $\left(\mathbf{X}_{2}\right)$ dengan Variabel Komitmen Organisasi (Y)}

Berdasarkan output SPSS di atas diperoleh konstanta kemiringan (a) $=9,178$ dan koefisien arah (b) $=0,905$. Dengan demikian, hubungan fungsional antara Komitmen Organisasi Widyaiswara KLHK dengan Kepuasan Kerja dapat dinyatakan dalam bentuk persamaan regresi $\hat{\mathbf{Y}}=\mathbf{9 , 1 7 8}+\mathbf{0 , 9 0 5 X _ { 2 }}$.

Dari tabel output SPSS di atas diketahui bahwa nilai koefisien korelasi antara $\mathrm{X}_{2}$ dengan $\mathrm{Y}\left(\mathrm{r}_{\mathrm{y} 2}\right)$ adalah sebesar 0,640 dan nilai probabilitasnya (signifikansi) sebesar 0,000 (kurang dari $0,05)$, sehingga korelasi antara $\mathrm{X}_{2}$ dengan $\mathrm{Y}\left(\mathrm{r}_{\mathrm{y} 2}\right)$ dinyatakan Positif dan sangat Signifikan. Dengan demikian maka $\mathrm{H}_{0}$ ditolak dan $\mathrm{H}_{1}$ diterima, sehingga dapat disimpulkan bahwa terdapat hubungan positif antara Kepuasan Kerja dengan Komitmen Organisasi Widyaiswara KLHK. 


\section{Hubungan antara Budaya Organisasi $\left(X_{1}\right)$ dan Kepuasan Kerja $\left(X_{2}\right)$ secara bersama-sama dengan Komitmen Organisasi (Y)}

Analisis regresi ganda digunakan untuk mengetahui hubungan sebab-akibat antara dua variabel bebas $\left(\mathrm{X}_{1}\right.$ dan $\left.\mathrm{X}_{2}\right)$ atau lebih secara bersama-sama dengan variabel terikat $(\mathrm{Y})$, sehingga diperoleh model persamaan sebagai berikut: $\hat{Y}=a+b_{1} X_{1}+b_{2} X_{2}$. Berdasarkan output SPSS di atas diperoleh nilai kemiringan $(a)=6,172$, nilai koefisien arah $\left(b_{1}\right)=0,610$ dan nilai koefisien arah $\left(b_{2}\right)=0,350$. Dengan demikian, hubungan fungsional antara Komitmen Organisasi Widyaiswara KLHK (Y) dengan Budaya Organisasi $\left(\mathrm{X}_{1}\right)$ dan Kepuasan Kerja $\left(\mathrm{X}_{2}\right)$ dapat dinyatakan dalam bentuk persamaan regresi $\hat{\mathbf{Y}}=\mathbf{6 , 1 7 2}+\mathbf{0 , 6 1 0 X} \mathbf{1}+\mathbf{0 , 3 5 0 X _ { 2 }}$.

Setelah diketahui besarnya koefisien korelasi ganda $\left(\mathrm{r}_{\mathrm{y} 12}\right)$, selanjutnya dihitung besarnya kontribusi (koefisien determinasi) Budaya Organisasi dan Kepuasan Kerja secara bersamasama terhadap Komitmen Organisasi Widyaiswara KLHK $\left(\mathrm{r}^{2} \mathrm{y} 12\right)$. Dari hasil perhitungan diperoleh nilai koefisien determinasi sebesar $(0,802)^{2}=0,6440$, yang dapat dimaknai bahwa $64,40 \%$ keragaman pada Komitmen Organisasi Widyaiswara KLHK dapat dijelaskan oleh Budaya Organisasi dan Kepuasan Kerja.

\section{Korelasi parsial}

Berdasarkan tabel output SPSS di atas diketahui nilai probabilitasnya (signifikansi) sebesar 0,000 , yang berarti kurang dari $\alpha(0,05)$, dengan demikian koefisien korelasi antara $\mathrm{X}_{1}$ dan $\mathrm{Y}$ dengan kontrol $\mathrm{X}_{2}$ sebesar 0,630 dinyatakan memiliki hubungan yang POSITIF dan sangat Signifikan.

Berdasarkan tabel output SPSS di atas diketahui nilai probabilitasnya (signifikansi.) sebesar 0,002 , yang berarti kurang dari $\alpha(0,05)$, dengan demikian koefisien korelasi antara $\mathrm{X}_{2}$ dan $\mathrm{Y}$ dengan kontrol $\mathrm{X}_{1}$ sebesar 0,306 dinyatakan memiliki hubungan yang POSITIF dan sangat Signifikan.

\section{PEMBAHASAN}

\section{Hubungan Antara Variabel Budaya Organisasi (X1) dengan Variabel Komitmen Organisasi (Y) \\ Berdasarkan data-data dan hasil perhitungan sebagaimana telah dijelaskan sebelumnya,} diperoleh bahwa terdapat hubungan yang positif dan signifikan antara budaya organisasi dengan komitmen organisasi Widyaiswara KLHK, sehingga dapat dimaknai bahwa jika budaya organisasi pada suatu lembaga diklat dipersepsikan baik oleh para widyaiswaranya maka komitmen organisasi widyaiswara tersebut terhadap lembaga diklatnya akan semakin tinggi. Kekuatan hubungan antara budaya organisasi dengan komitmen organisasi Widyaiswara KLHK tercermin pada nilai koefisien korelasi yang begitu besar, yaitu 0,779.

Hasil penelitian ini sejalan dengan hasil penelitian Ghorbanhosseini (2013:23) yang dimuat dalam Tehnički Vjesnik Journal, Volume 20 No. 6: 1024, dengan judul "The Effect of Organizational Culture, Teamwork and Organizational Development on Organizational Commitment: The Mediating Role of Human Capital", yang mendapati bahwa budaya organisasi secara positif mempengaruhi komitmen organisasi dengan nilai koefisien korelasi (r) sebesar $=0,51$ pada $\mathrm{p}<0,01$ dan nilai koefisien determinasinya $\left(\mathrm{r}^{2}\right)$ sebesar 0,26 . Demikian pula dengan hasil penelitian Azizollah, Abolghasem, and Amin (2016:30), yang dimuat dalam Global Journal of Health Science, Volume 8 No. 7: 200, dengan judul "The Relationship Between Organizational Culture and Organizational Commitment in Zahedan University of Medical Sciences", yang juga berkesimpulan bahwa terdapat hubungan yang positif dan signifikan antara budaya organisasi dan komitmen organisasi dengan nilai koefisien korelasi (r) sebesar 0,419 dan nilai koefisien determinasi $\left(\mathrm{r}^{2}\right)$ sebesar 0,18 . 
Berdasarkan uraian di atas maka dapat disimpulkan bahwa budaya organisasi pada suatu lembaga diklat merupakan salah satu faktor yang sangat menentukan dalam meningkatkan komitmen organisasi Widyaiswara KLHK terhadap lembaga diklatnya.

\section{Hubungan Antara Kepuasan Kerja (X2) dengan Variabel Komitmen Organisasi (Y)}

Sama halnya dengan penjelasaan sebelumnya, dari hasil penelitian ini diperoleh juga fakta bahwa terdapat hubungan yang positif dan signifikan antara kepuasan kerja dengan komitmen organisasi Widyaiswara KLHK, yang juga dapat dimaknai bahwa jika kepuasan kerja widyaiswara pada suatu lembaga diklat tinggi maka komitmen organisasi widyaiswara tersebut terhadap lembaga diklatnya akan semakin tinggi pula. Kekuatan hubungan antara kepuasan kerja dengan komitmen organisasi Widyaiswara KLHK tercermin pada nilai koefisien korelasi yang besar, yaitu 0,640. Begitu pula keragaman pada komitmen organisasi Widyaiswara KLHK yang terkait erat dengan kepuasan kerja, yang dicerminkan dengan nilai koefisien determinasinya $\left(\mathrm{r}_{\mathrm{y} 2}^{2}\right)$ yang juga besar, yaitu 0,4096, sehingga dapat dimaknai bahwa $40,96 \%$ keragaman pada komitmen organisasi Widyaiswara KLHK dapat dijelaskan oleh kepuasan kerja sedangkan 59,04\% sisanya dipengaruhi oleh faktor-faktor yang lainnya.

Hasil penelitian ini sejalan dengan hasil penelitian Fatema and Muath (2013:21), yang dimuat dalam International Journal of Business, Humanities and Technology, Volume 3 No. 5: 48, dengan judul "Job Satisfaction and Organizational Commitment: A Correlational Study in Bahrain" yang menyimpulkan bahwa terdapat hubungan yang kuat (positif) antara kepuasan kerja dan komitmen organisasional. Demikian pula dengan hasil penelitian Mosadeghrad and Ferdosi (2013:31), yang dimuat dalam Materiasociomedica, Journal of the Academy of Medical Sciences of Bosnia and Herzegovina, Volume 25 No. 2:123, dengan judul "Leadership, Job Satisfaction and Organizational Commitment in Healthcare Sector: Proposing and Testing a Model", yang mendapatkan bahwa ada hubungan yang signifikan secara statistik antara kepuasan kerja karyawan dan komitmen organisasionalnya.

Berdasarkan uraian di atas maka dapat disimpulkan bahwa kepuasan kerja widyaiswara pada suatu lembaga diklat merupakan salah satu faktor yang juga menentukan dalam meningkatkan komitmen organisasi Widyaiswara KLHK terhadap lembaga diklatnya.

\section{Hubungan antara variabel Budaya Organisasi $\left(X_{1}\right)$, variabel Kepuasan Kerja $\left(X_{2}\right)$ Secara Bersama-sama dengan Komitmen Organisasi (Y)}

dalam penelitan ini juga diperoleh fakta bahwa terdapat huhungan yang positif dan signifikan antara budaya organisasi dan kepuasan kerja secara bersama-sama dengan komitmen organisasi Widyaiswara KLHK, yang dapat dimaknai bahwa jika budaya organisasi pada suatu lembaga diklat baik dan kepuasan kerja widyaiswaranya tinggi maka komitmen organisasi Widyaiswara KLHK terhadap lembaga diklatnya akan tinggi pula Kekuatan hubungan antara budaya organisasi dan kepuasan kerja secara bersama-sama dengan komitmen organisasi Widyaiswara KLHK tercermin pada nilai koefisien korelasi gandanya yang begitu besar, yaitu 0,802, yang menurut Kategori Guilford dapat digolongkan sebagai hubungan yang kuat (high correlation).

Berdasarkan uraian di atas maka dapat disimpulkan bahwa budaya organisasi dan kepuasan kerja widyaiswara pada suatu lembaga diklat merupakan faktor yang sangat menentukan dalam meningkatkan komitmen organisasi Widyaiswara KLHK terhadap lembaga diklatnya. Fakta ini semakin memperkuat berbagai teori dan hasil-hasil penelitian sebelumnya yang menyebutkan bahwa faktor-faktor yang dapat mempengaruhi komitmen seseorang terhadap organisasinya adalah sebagai berikut : disiplin kerja, motivasi kerja, keterlibatan kerja, kecerdasan emosional, komunikasi interpersonal, kepemimpinan transformasional pimpinan organisasi, kebijakan pemerintah, budaya organisasi dan kepuasan kerja. Selain itu dari 
penelitian ini juga dapat diketahui bahwa faktor budaya organisasi $(0,779)$ lebih dominan dari pada faktor kepuasan kerja $(0,640)$.

Berdasarkan penilaian dari pakar (expert judgment) dan analisis dari peneliti, maka dapat disusun bobot urutan prioritas indikator-indikator yang perlu dengan segera diperbaiki dan yang perlu dipertahankan dan dikembangkan seperti gambar rekapitulasi hasil akhir analisis SITOREM berikut ini.

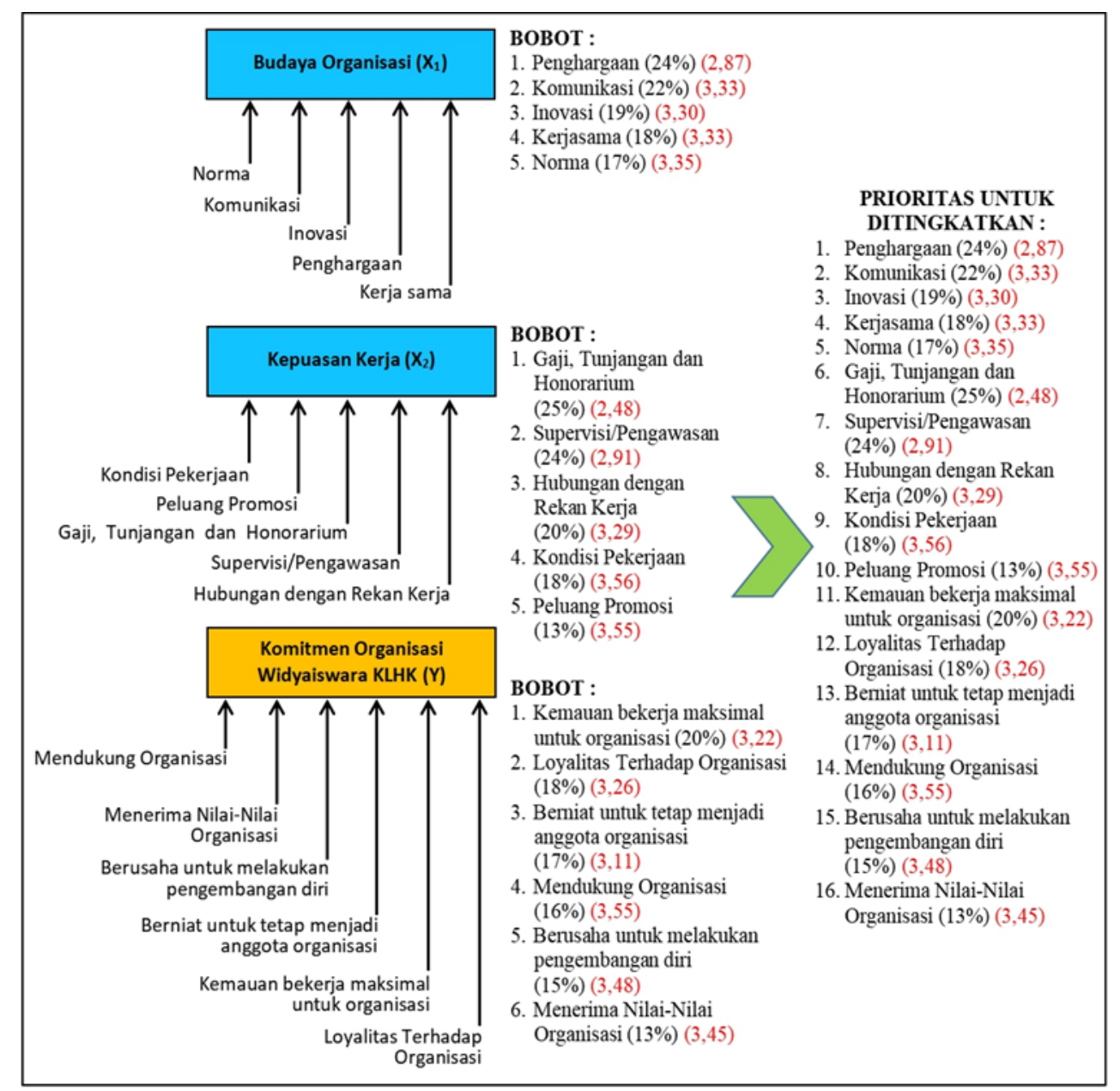

\section{SIMPULAN}

Berdasarkan analisis terhadap data hasil penelitian dapat disimpulkan terdapat hubungan positif sangat signifikan antara Budaya Organisasi dengan Komitmen Organisasi, antara kepuasan kerja dengan Komitmen Organisasi dan antara Budaya Organisasi dan kepuasan kerja bersama-sama dengan Komitmen Organisasi. Berdasarkan hasil penelitian ini maka untuk meningkatkan Komitmen Organisasi dapat dilakukan dengan meningkatkan budaya organisasi dan perbaikan pada kepuasan kerja.

\section{DAFTAR PUSTAKA}

Ali Mohammad Mosadeghrad \& Masoud Ferdosi. 2013. Leadership, Job Satisfaction and Organizational Commitment in Healthcare Sector: Proposing and Testing a Model. Materiasociomedica, Journal of the Academy of Medical Sciences of Bosnia and Herzegovina. Volume 25 No. 2:123. 
Arbabisarjou Azizollah, Farhang Abolghasem \& Dadgar Mohammad Amin. 2016. The Relationship Between Organizational Culture and Organizational Commitment in Zahedan University of Medical Sciences. Global Journal of Health Science. Volume 8 No. 7: 200.

Fatema Mohammed \& Muath Eleswed. 2013. Job Satisfaction and Organizational Commitment: A Correlational Study in Bahrain. International Journal of Business, Humanities and Technology. Volume 3 No. 5: 48.

Guilford, J.P. 1956. Fundamental Statistics in Psychology and Education. New York: McGraw Hill.

Hidayat, Rais. 2017. Tinjauan Teoretik Tentang Komitmen Organisasi. PEDAGONAL, Jurnal Ilmiah Pendidikan, Vol. 1 No. 2, 62 - 70.

Hardhienata, S. 2017. The Development of Scientific Identification Theory to Conduct Operation Research in Education Management. IOP Conference Series: Material Science and Engineering. Vol 166, 2017, doi: 10.1088/1757-899X/166/I/012017.

Masoud Ghorbanhosseini. 2013. The Effect of Organizational Culture, Teamwork and Organizational Development on Organizational Commitment: The Mediating Role of Human Capital. Tehnički Vjesnik Journal. Volume 20 No. 6: 1024..

Kreitner, R. \& Kinicki, A. (2010). Organizational Behaviour. $9^{\mathrm{TH}}$ (ninth) Edition. New York: Mc. Grow- Hill.

Robbins, S. \& Judge, T.A. (2015). Perilaku Organisasi. Terjemahan Ratna Saraswati dan Febriella Sirait. Jakarta: Penerbit Salemba.

Schermerhorn Jr.,J.R.,Osborn,R.N.,Uhl-Bien,M.,Hunt,J.G. ～(2012). Organizational Behaviour. $12^{\text {th }}$ edition. New York: John Wiley \& Sons, Inc. 